\title{
Voice of NESON
}

Krishna Sharma, MS, DNB

Department of Neurosurgery

Nepal Medical College

Kathmandu, Nepal

$\mathrm{N}$ epalese Society of Neurosurgeons is a society of all neurosurgeons of Nepal where we can share our knowledge, experience, joy, problems and sorrow. It is a platform where young neurosurgeons can avail the guidance on development of their career and avail the opportunity of further training. Since the last annual conference, the process of formation of chapters on subspecialty has started with the formation of Neuro-spine chapter to begin with. In the era of development of sub-specialty in Neurosurgery, the society attempts to help all neurosurgeon to focus in one or more subspecialty and develop accordingly. With the regular CME in turn by all the major hospitals in Nepal where neurosurgical services are provided, we can share and learn from one's or other's work. There were many scientific paper presentations from almost all hospital of Nepal in the last annual conference in October. Now, the $1^{\text {st }}$ International $\& 5^{\text {th }}$ Annual Conference of Nepalese Society of Neurosurgeons (INCONESON 2017), due from March $8^{\text {th }}$ to $11^{\text {th }}$, is approaching. The detailed information is available in our website, www.neson.org.np. It is another opportunity to present your work and share your experiences. Many eminent neurosurgeons from all around the world have confirmed their participation in the conference. We are also having workshop moderated by world-renowned neurosurgeons under the flags of WFNS, AANS \& ACNS. So, let us participate in the workshops and the conference and take full advantage from the events. Under the leadership of Dr. Prabin Shrestha, Nepal Journal of Neurosciences, the official journal of NESON, is regularly being published, improving its quality every time. It is yet another great opportunity to publish your work and share it with the whole world as well as increase one's academic currency. Now 2016 is coming to its end and 2017 is coming with new hopes and avenues. Let us all welcome 2017 with fresh determinations to do even better that before for oneself, for Nepal and for the whole world.

Happy New Year 2017. 